\title{
A Novel Strain of Moderately Thermophilic Streptomyces from the Fenjiu-Flavor Daqu
}

\author{
Lihong Zhang*, Baoyan Guo, Huiqing Yang, Caihui Wang \\ College of Life Sciences, Shanxi Normal University, Taiyuan, China \\ Email: *zhangyongyuan0@163.com
}

How to cite this paper: Zhang, L.H., Guo, B.Y., Yang, H.Q. and Wang, C.H. (2022) A Novel Strain of Moderately Thermophilic Streptomyces from the Fenjiu-Flavor Daqu. Open Access Library Journal, 9: e8388. https://doi.org/10.4236/oalib.1108388

Received: January 21, 2022

Accepted: February 12, 2022

Published: February 15, 2022

Copyright $\odot 2022$ by author(s) and Open Access Library Inc.

This work is licensed under the Creative Commons Attribution International License (CC BY 4.0).

http://creativecommons.org/licenses/by/4.0/ (c) (i) Open Access

\begin{abstract}
Fenjiu-flavour Daqu is an important starter to support growth of microorganisms in the fermented process of Fenjiu-flavor liquor. A novel thermophilic microorganism, designated strain gbyl, was isolated from Fenjiu-flavour Daqu from Shanxi Xinghuacun Fenjiu Distillery Company Limited, Fenyang country, Shanxi province. The morphological, physiological, chemical taxonomic and phylogenetic characteristics of the strain were described in this paper. The isolate gbyl exhibited higher heat resistance. The strain is aerobes, non-motile, and spore forming bacteria. The strain can produce amylase, lipase. The physiological tests combined with $16 \mathrm{~S}$ rDNA-based molecular analysis, gbyl was identified as a moderately thermophilic Streptomyces. In the paper, the thermophilic Streptomyces sp. gbyl is isolated and identified for the first time in Fen-Daqu. The results offer a reference for the comprehensive understanding of bacterial diversity of Fen-Daqu.
\end{abstract}

\section{Subject Areas}

Microbiology

\section{Keywords}

Fen-Daqu, Moderately Thermophilic Actinobacteria, Streptomyces

\section{Introduction}

Baijiu is the national liquor of China and the world's most consumed spirit, which is produced using a unique and traditional solid-state fermentation (SSF) process. Daqu plays a vital role in the formation of Baijiu flavor (Deng et al., 2021 [1]; Ye et al., 2021 [2]). Fen-Daqu is the main source of microorganisms in the brewing process of Fen-flavor liquor, and a rich microbial population will be formed in the traditional Daqu brewing process. Some studies have found that the microorganisms in Daqu include fungi and bacteria (Cao et al., 2015 [3]; 
Chang et al., 2018 [4]; Chen et al., 2021 [5]; Luo et al., 2013 [6]). As Daqu is in a high temperature environment, heat-resistant groups compete for continuous reproduction and metabolism, temperature has become the main driving force for the formation of Daqu flora. Chinese Fenjiu liquor has been made for 1500 years and is distilled from the product of fermentation using a wild microbial starter, Fenjiu-flavor Daqu. In general, the maximum temperature while making fen-flavor can reach $50^{\circ} \mathrm{C}$. Bacillus spp., which are heat-resistant microbe have been considered, however, the roles of other thermophilic microbes in the formation of Fen-Daqu have not been confirmed.

Thermophilic actinobacteria thrive at relatively high temperatures ranging from $40^{\circ} \mathrm{C}$ to $80^{\circ} \mathrm{C}$ (Tortora et al., 2007) [7]. The moderately thermophilic actinobacteria require $45^{\circ} \mathrm{C}-55^{\circ} \mathrm{C}$ for optimum growth (Jiang and $\mathrm{Xu}, 1993$ ) [8]. Many thermophilic strains have been reported in thermophilic actinobacteria. Thermophilic actinobacteria are known to possess unique metabolic rates and physical properties that prove to be beneficial in a variety of ecological roles such as composting, antimicrobial activity, plant growth promotion, nitrogen fixation, hypersensitivity pneumonitis (Shivlata and Satyanarayana, 2015 [9]; Wu et al., 2016 [10]; You et al., 2013 [11]). Thermophilic actinobacteria have been proven as a potential source of bioactive compounds and richest source of secondary metabolites. They are the most economically and biotechnologically valuable microorganisms (Singh et al., 2012) [12].

The aim of this work was to investigate the thermophilic actinobacteria from Daqu ecosystems by the culture-dependent methods. Therefore, we explored the thermophilic actinobacteria in Fen-Daqu. The characterization of thermophilic actinobacteria was achieved by analysis of morphology, optimum temperature, enzyme production activity, antibacteia activity, and 16S rRNA gene sequence.

\section{Materials and Methods}

\subsection{Materials}

\subsubsection{Daqu Samples}

Daqu samples were provided from Shanxi Xinghuacun Fenjiu Distillery Company Limited, Fenyang country, Shanxi province. The Company produces typical light-liquor brewing by Daqu.

\subsubsection{Medium}

The actinobacteria medium was prepared as described previously (Wei et al., 2019 [13]; Zhang et al., 2019 [14]). IPS2 medium (composed of Yeast extract 4 g, Malt extract 5 g, Dextrose 4 g, Agar 18 g, pH 7.3, Nutrient solution (Daqu 10 g, Corn flour $10 \mathrm{~g}$ ), $\mathrm{ddH}_{2} \mathrm{O} 1 \mathrm{~L}, \mathrm{pH}$ 7.3. Gauss No. 1 medium (composed of composed of starch soluble $20 \mathrm{~g}, \mathrm{KNO}_{3} 1 \mathrm{~g}, \mathrm{~K}_{2} \mathrm{HPO}_{4} 0.5 \mathrm{~g}, \mathrm{MgSO}_{4} \cdot 7 \mathrm{H}_{2} \mathrm{O} 0.5 \mathrm{~g}, \mathrm{NaCl}$ $0.5 \mathrm{~g}, \mathrm{FeSO}_{4} \cdot 7 \mathrm{H}_{2} \mathrm{O}, 0.01 \mathrm{~g}$, Agar $15-20 \mathrm{~g}$, dd $\mathrm{d}_{2} \mathrm{O} 1 \mathrm{~L}$, adjusting $\mathrm{pH}$ to 7.4 - 7.6). Gauss No.2 medium (composed of glucose $5 \mathrm{~g}$, peptone $2.5 \mathrm{~g}$, NaCl $2.5 \mathrm{~g}$, Agar $10 \mathrm{~g}$, ddH $\mathrm{d}_{2} \mathrm{O} 500 \mathrm{~mL}$, Nutrient solution $5 \mathrm{ml}$, pH 7.2). IPS4 medium (composed of starch soluble $5 \mathrm{~g}, \mathrm{~K}_{2} \mathrm{HPO}_{4} 0.5 \mathrm{~g}, \mathrm{MgSO}_{4} \cdot 7 \mathrm{H}_{2} \mathrm{O} 0.5 \mathrm{~g}, \mathrm{NaCl} 0.5 \mathrm{~g},\left(\mathrm{NH}_{4}\right)_{2} \mathrm{SO}_{4} 1$ 
g, $\mathrm{CaCO}_{3} 1 \mathrm{~g}, \mathrm{FeSO}_{4} \cdot 7 \mathrm{H}_{2} \mathrm{O} 0.0005 \mathrm{~g}, \mathrm{MnSO}_{4} \cdot 7 \mathrm{H}_{2} \mathrm{O} 0.0005 \mathrm{~g}$, Agar $10 \mathrm{~g}$, Nutrient solution $5 \mathrm{ml}$, ddH $\mathrm{de}_{2} \mathrm{O} 0 \mathrm{~mL}$ ).

\subsection{Methods}

\subsubsection{Isolation of Thermophilic Actinobacteria from Daqu}

Serial dilution and spread-plate techniques (Williams et al., 1965) [15] were used to isolate actinomycetes from Daqu samples. Four agar media were tested: IPS2, Gauss No. 1, Gauss No. 2, IPS4 medium. $10 \mathrm{~g}$ Daqu sample with $90 \mathrm{ml}$ sterile water, set the original solution number as $10^{-1}$, shake and dilute the original sample of bacteria to be tested fully, then transfer $1 \mathrm{ml}$ original sample with sterile pipette to $9 \mathrm{ml}$ sterile water, $10^{-2}$, and dilute to $10^{-6}, 0.2 \mathrm{ml}$ of diluted bacterial solution were added to the corresponding numbered solid medium. All media were supplemented with $25 \mathrm{mg} \cdot \mathrm{mL}^{-1}$ Nalidixic acid and $10 \mathrm{mg} \cdot \mathrm{mL}^{-1} \mathrm{Am}$ photeric to inhibit the growth of bacteria and fungi. All plates were incubated at $45^{\circ} \mathrm{C}$ for 3 days. Actinomycete colonies were identified by visual examination of the cultural and morphological characteristics; microscopic examination was performed if needed. The isolated and purified high-temperature resistant strains were streaked on the prepared solid plate and cultured at $45^{\circ} \mathrm{C}$ for 4 days to observe the growth of each strain. According to the size of the colony, the color of mycelia and the number of aerial mycelia, the growth state of the strain in different media was judged, and the appropriate basic media was selected.

\subsubsection{Temperature Range of Actinomycetes}

The strains were inoculated on ISP2 medium for activation for 3 days, and cultured at seven temperature gradients of $25^{\circ} \mathrm{C}, 30^{\circ} \mathrm{C}, 40^{\circ} \mathrm{C}, 45^{\circ} \mathrm{C}, 50^{\circ} \mathrm{C}, 55^{\circ} \mathrm{C}$ and $60^{\circ} \mathrm{C}$, respectively. Three groups were set at each temperature. The activated strains were cultured for 3 days, and the colony size was observed. After that, the cross measuring method was used to measure the size of the colony diameter to determine the optimum growth temperature of the strain.

\subsubsection{Morphological Characterization and Biochemical Tests}

The selected isolate was grown in ISP2 solid medium in preparation for colony morphology observation. Cultures grown on ISP2 agar for 3 days at $45^{\circ} \mathrm{C}$ was observed by light microscopy. Scanning electron microscopy was used to observe mature spores on aerial mucelium of the isolates grown on ISP2 for 3 days at $45^{\circ} \mathrm{C}$. Gram staining was performed as described by Harrigan et al. (1968) [16]. The assays for enzyme activity (Li et al., 2016) [17] is used for inferring the function in Daqu. The antimicrobial activity of gby1 isolated on ISP2 was analyzed using an agar block method (Stern et al., 2006) [18] against 3 bacterial species, which were provided by the Microbiology Laboratory in Shanxi Normal University. The bacterial species included Escherichia coli, Staphylococcus aureus, and Bacillus subtilis.

\subsubsection{Phylogenetic Analysis}

The isolate was identified by $16 \mathrm{~S}$ DNA-based sequence analysis. Actinomycete 
DNA was extracted from pure isolates using the method described by Saito and Miura (Saito and Miura, 1963) [19]. Partial 16S rRNA gene fragments were amplified by polymerase chain reaction (PCR) using the forward primer used was p27f (5'-AGAGTTTGATCCTGGCTCAG-3'), whereas the reverse primer was p1492r (5'-TACGGCTACCTTGTTACGACTT-3'). PCR reaction $(50 \mu \mathrm{L})$ contained the following: a hot start performed at $95^{\circ} \mathrm{C}$ for $5 \mathrm{~min}$ and 30 cycles at $95^{\circ} \mathrm{C}$ for $30 \mathrm{~s}, 56^{\circ} \mathrm{C}$ for $1 \mathrm{~min}$, and $72^{\circ} \mathrm{C}$ for $2 \mathrm{~min}$, followed by a final extension performed at $72^{\circ} \mathrm{C}$ for $10 \mathrm{~min}$. PCR reactions were purified and sequenced by Beijing Tsingke Biotech Co., Ltd. MEGA5.0 was used to analyze the phylogeny and molecular evolution of the strain. The sequences were then compared with BLAST search sequences from the National Center for Biotechnology Information (NCBI) to find similar nucleotide sequences. The obtained sequence was compared with available reference sequences in the EMBL/GenBank/DDBJ databases and deposited in GeneBank under the accession No. MZ156984.

\section{Results}

The suspension was spread onto the surface of ISP2 agar plates and incubated at $45^{\circ} \mathrm{C}$ for 3 days. Strain gbyl was isolated from this medium.

\subsection{The Cultural Characteristics of the Isolate gby1 on Different Media}

The cultural characteristics of the isolate gbyl are summarized in Table 1. There were great differences in the growth state of the strain in different media. The isolate grew well on ISP2 medium, followed by Gauss No.2. It grows poorly in ISP4 and Gauss No.1. The isolate did not produce diffusible pigments on any medium (Table 1).

\subsection{The Optimum Temperature of Streptomyces sp. gby 1}

Growth temperature was measured on ISP2 medium at $25^{\circ} \mathrm{C}-60^{\circ} \mathrm{C}$. The strain Streptomyces sp. gbyl could grow at $25^{\circ} \mathrm{C}-55^{\circ} \mathrm{C}$ and the optimum temperature is $45^{\circ} \mathrm{C}$ (Figure 1 ). The results showed gbyl belongs to the moderately thermophilic actinomycetes.

Table 1. The colonies characteristics of gbyl on four different media at $45^{\circ} \mathrm{C}$.

\begin{tabular}{ccccc}
\hline Medium Type & ISP2 & ISP4 & Gauss No.1 & Gauss No.2 \\
Characteristics & $\begin{array}{c}\text { Dense and } \\
\text { exuberant }\end{array}$ & Less & Less & More \\
Aerial mycelium & Yellowish brown & White & White & Light yellow \\
Substrate hyphae & White & White & White & White \\
Spores & Larger & Smaller & Smaller & Larger \\
\hline
\end{tabular}




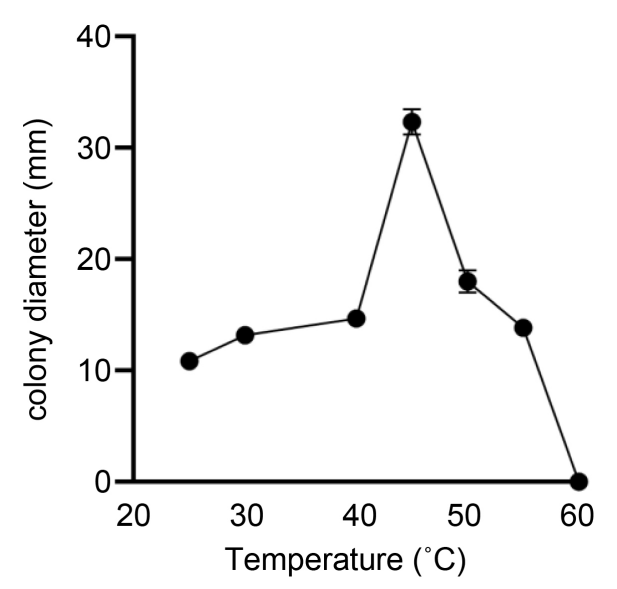

Figure 1. The growth of Streptomyces sp. gbyl on ISP2 medium at different temperatures.
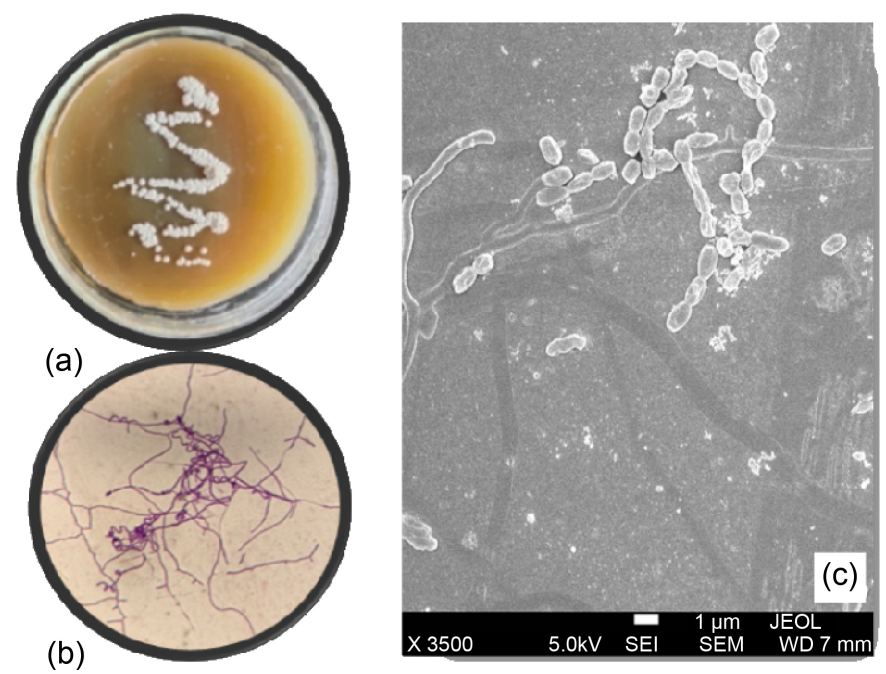

Figure 2. The morphological characterization of the isolate gbyl on ISP2 medium. (a) Colony morphology; (b) Aerial mycelium formation and spore filament $(10 \times 100)$; (c) Scanning electron microphotograph of the isolate gbyl.

\subsection{Morphological Characterization and Biochemical Tests}

Morphological characteristics were observed under light microscopy (Figure 2(b)) and scanning electron microscopy (Figure 2(c)) after incubation for 3 days on ISP2 medium at $45{ }^{\circ} \mathrm{C}$, it could be observed that the colony morphology was small, with fine and dense mycelia. The colony surface was dry and powdery, difficult to stir up (Figure 2(a)). The experimental results showed that the strain did not produce protease and cellulose. It was discovered the isolate gbyl markedly suppressed Escherichia coli and Staphylococcus aureus (Table 2).

\subsection{S rDNA Sequencing and Phylogenetic Analysis of gby1}

We used a $16 \mathrm{~S}$ rDNA gene sequence-based strategy to identify the isolate gby1. The 16S rDNA was sequenced and is available at GenBank under accession 


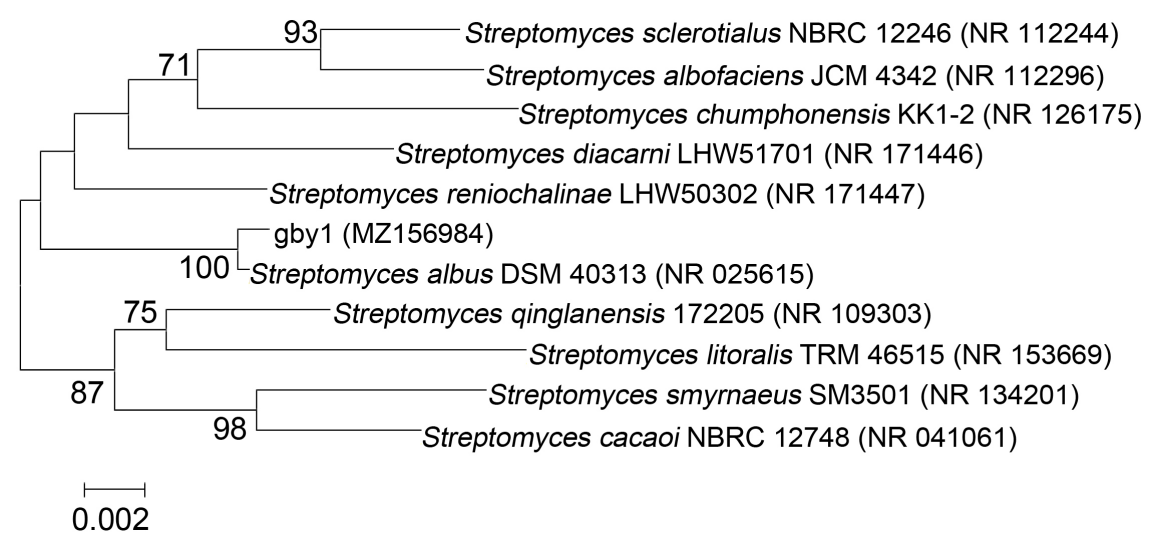

Figure 3. Phylogenetic tree constructed after multiple alignments using CLUSTAL-X of the 16S rDNA gene sequences available from the GenBank/EMBL/DDBJ database (accession numbers are given in parentheses) (Thompson et al. 1997) [20]. the tree was constructed with MEGA 5 using the neighbor-joining with bootstrap values calculated from 1000 trees based on 1377 base pairs of the 16S rDNA gene of sequences of the isolate gby1 (GenBank accession number MZ156984). The scale bar indicates the 0.002 evolutionary distance unit.

Table 2. The morphologica, biochemical characteristics and antagonistic activity.

\begin{tabular}{cc}
\hline Characteristics & Result \\
\hline Gram staining & Positive \\
Shape and growth & Filamentous aerial growth \\
Range of temperature for growth & $25^{\circ} \mathrm{C}-55^{\circ} \mathrm{C}$ \\
Optimum temperature & $45^{\circ} \mathrm{C}$ \\
Range of pH for growth & $6-8$ \\
Amylase & + \\
Protease & - \\
Lipase & + \\
Cellulase & - \\
Tested microbes & \\
Escherichia coli & + \\
Staphylococcus aureus & + \\
Bacillus subtilis & - \\
\hline
\end{tabular}

MZ156984. A phylogenetic tree was constructed based on an alignment of the sequences (Figure 3). Based on 16S rRNA gene sequence analysis, sequence similarity calculations indicated that the isolate gbyl showed the greatest degree of similarity to Streptomyces albus (NR025615) 99.93\%.

\section{Discussion}

Traditional Chinese liquor (Baijiu) solid state fermentation technology has lasted for several thousand years. The microbial communities that enrich in liquor starter are important for fermentation. However, the microbial communities 
are still under-characterized (Huang et al., 2017) [21]. Some thermophilic microbes were investigated using culture-dependent and culture-independent technology. Xiao et al. pointed that bio-heat functioned as a primary endogenous driver promoting the formation of functional MT-Daqu microbiota. The thermotolerant strains, survived or kept on growing from day 4 to day 12 , might contribute to the formation of flavor metabolites (Xiao et al., 2017) [22]. In 2014, the thermotolerant and thermophilic microbes were showed that using DGGE technology in the Chinese "Baiyunbian" liquor Daqu, the most dominant bacterial species were Bacillus and Virgibacillus, followed by Lactobacillus and Trichococcus (Xiong et al., 2014) [23]. In 2021, Thermoactinomyces daqus $\mathrm{H}-18^{\mathrm{T}}$ was isolated at $55^{\circ} \mathrm{C}$ from a high-temperature Daqu sample collected from the manufacturing process of a sesame-flavoured liquor in Shandong province, China (Yao et al., 2014) [24]. Some thermophilic microorganisms were showed using metatranscriptomics method from Chinese Luzhou-flavor baijiu. The authors inferred that thermophilic microorganisms might bring significant effects in aged pit mud (Zhou et al., 2021) [25].

In our previous studies, we found that most of the medium temperature actinomycetes from Fen-jiu Daqu belong to Streptomyces (Zhang et al., 2019) [14]. Interestingly, the thermophilic actinomycetes gbyl also belong to Streptomyces. However, the comparison of $16 \mathrm{~S}$ rDNA sequences showed that there were significant differences between the thermophilic Streptomyces sp. gbyl and medium temperature Streptomyces spp. In 2019, Wei found 3 Thermoactinomycetaceae strains including Shimazuella kribbensis, Kroppenstedtia sanguinis and Kroppenstedtia eburne in Niulanshan-flavor baijiu (Wei JW., 2019). In the paper, the thermophilic Streptomyces sp. gbyl is isolated and identified for the first time in Fen-Daqu. Further studies are required to clarify the role and mechanism of action of the thermophilic actinomycetes, which needs to be further studied.

\section{Acknowledgements}

The financial support of the experimental studies and publication was realized by undergraduate training programs for innovation and entrepreneurship from Shanxi Normal University (2019DCXM-84), the excellent course of Shanxi Normal University (2019YZKC-10).

\section{Conflicts of Interest}

The authors declare no conflicts of interest.

\section{References}

[1] Deng, Y., Huang, D., Han, B., Ning, X., Yu, D., Guo, H., Zou, Y., Jing, W. and Luo H. (2021) Correlation: Between Autochthonous Microbial Diversity and Volatile Metabolites during the Fermentation of Nongxiang Daqu. Frontiers in Microbiology, 12, Article ID: 688981. https://doi.org/10.3389/fmicb.2021.688981

[2] Ye, H., Wang, J., Shi, J., Du, J., Zhou, Y., Huang, M. and Sun B. (2021) Automatic and Intelligent Technologies of Solid-State Fermentation Process of Baijiu Produc- 
tion: Applications, Challenges, and Prospects. Foods, 10, Article No. 680. https://doi.org/10.3390/foods 10030680

[3] Cao, X.Z., You, J.M., Ming, H.M., Liu, J. and Ren, L. (2015) Isolation and Identification of Yeasts from Luzhou Flavor Daqu. Advances in Microbiology, 5, 307-310. https://doi.org/10.4236/aim.2015.55030

[4] Chang, S.U., Dou, X., Xin, Y.E., Ying-Ying, M.A. and Yang, J.G. (2018) Isolation and Identification of Mold from Daqu in Different Periods Based on the ITS4/5 rRNA Region Sequence. Modern Food Science and Technology, 34, 54-58+211.

[5] Chen, Y., Li, K., Liu, T., Li, R., Fu, G., Wan, Y. and Zheng F. (2021) Analysis of Difference in Microbial Community and Physicochemical Indices between Surface and Central Parts of Chinese Special-Flavor Baijiu Daqu. Frontiers in Microbiology, 11, Article ID: 592421. https://doi.org/10.3389/fmicb.2020.592421

[6] Luo, H.B., Yang, X.D., Yang, Y.H., Ye, G.B. and Li, D.Y. (2013) Isolation, Identification and Phylogenetic Analysis of Culturable Fungi in Luzhou-Flavor Daqu. Modern Food Science and Technology, 29, 2047-2052.

[7] Tortora, G.J., Funke, B.R. and Case, C.L. (2007) Microbiology: An Introduction. Pearson Benjamin Cummings, San Francisco.

[8] Jiang, C. and Xu, L. (1993) Actinomycete Diversity in Unusual Habitats. Actinomycetes, 4, 47-57.

[9] Shivlata, L. and Satyanarayana, T. (2015) Thermophilic and Alkaliphilic Actinobacteria: Biology and Potential Applications. Frontiers in Microbiology, 6, Article No. 1014.

[10] Wu, H., Liu, B. and Pan, S. (2016) Saccharopolyspora subtropica sp. nov., a Thermophilic Actinomycete Isolated from Soil of a Sugar Cane Field. International Journal of Systematic and Evolutionary Microbiology, 66, 1990-1995. https://doi.org/10.1099/ijsem.0.000976

[11] You, Z.Q., Li, J., Qin, S., Tian, X.P., Wang, F.Z. and Zhang, S. (2013) Georgenia sediminis sp. nov., a Moderately thermophilic actinobacterium Isolated from Sediment. International Journal of Systematic and Evolutionary Microbiology, 63, 4243-4247. https://doi.org/10.1099/ijs.0.051714-0

[12] Singh, R., Kapoor, V. and Kumar V. (2012) Utilization of Agro-industrial Wastes for the Simultaneous Production of Amylase and Xylanase by Thermophilic Actinomycetes. Brazilian Journal of Microbiology, 43, 1545-1552. https://doi.org/10.1590/S1517-83822012000400039

[13] Wei, J. (2019) Isolation and Identification of Cultivable Thermoactinomycetaceae in the Production of Qingxiang Baijiu. Liquor-Making Science and Technology, 1, 56-64. (Article in Chinese)

[14] Zhang, L., An, Q., Zhang, Y., Zhang, X., Lyu, P., Li, X. and Hu, Q. (2019) Evaluation of the Potential of Daqu-Derived Actinobacteria for Light-Flavour Chinese Liquor. Journal of Food Science and Technology, 7, 1-9.

[15] Williams, S. and Davies, F. (1965) Use of Antibiotics for Selective Isolation and Enumeration of Actinomycetes in Soil. Microbiology, 38, 251-261.

https://doi.org/10.1099/00221287-38-2-251

[16] Harrigan, W.F., MacCance, M.E., Acha, I.G., Villanueva, J.R. (1968) Metodos de laboratorio en microbiologia. Editorial Academia, Leon.

[17] Li, Q., Chen, X., Jiang, Y. and Jiang C.L. (2016) Cultural, Physiological, and Biochemical Identification of Actinobacteria. In: Dhanasekaran, D. and Jiang, Y., Eds., Actinobacteria: Basics and Biotechnological Applications, IntechOpen, London, 
88-111. https://doi.org/10.5772/61462

[18] Stern, N.J., Svetoch, E.A., Eruslanov, B.V., Perelygin, V.V., Mitsevich, E.V., Mitsevich, I.P., Pokhilenko, V.D., Levchuk, V.P, Svetoch, O.E. and Seal, B.S. (2006) Isolation of a Lactobacillus salivarius Strain and Purification of Its Bacteriocin, Which Is Inhibitory to Campylobacter jejuni in the Chicken Gastrointestinal System. Antimicrobial Agents and Chemotherapy, 50, 3111-3116.

https://doi.org/10.1128/AAC.00259-06

[19] Saito, H. and Miura, K.I. (1963) Preparation of Transforming Deoxyribonucleic Acid by Phenol Treatment. Biochimica et Biophysica Acta (BBA): Gene Structure, 72, 619-629.

[20] Thompson, J.D, Gibson, T.J., Plewniak, F., Jeanmougin, F. and Higgins, D.G. (1997) The CLUSTAL_X Windows Interface: Flexible Strategies for Multiple Sequence Alignment Aided by Quality Analysis Tools. Nucleic Acids Research, 25, 4876-4882. https://doi.org/10.1093/nar/25.24.4876

[21] Huang, Y., Yi, Z., Jin, Y., Zhao, Y., He, K., Liu, D., Zhao, D., He, H., Luo, H., Zhang, W., Fang, Y. and Zhao, H. (2017) New Microbial Resource: Microbial Diversity, Function and Dynamics in Chinese Liquor Starter. Scientific Reports, 7, Article No. 14577.

[22] Xiao, C., Lu, Z.M., Zhang, X.J., Wang, S.T., Ao, L., Shen, C.H., Shi, J.S. and Xu, Z.H. (2017) Bio-Heat Is a Key Environmental Driver Shaping the Microbial Community of Medium-Temperature Daqu. Applied and Environmental Microbiology, 83, Article ID: e01550-17. https://doi.org/10.1128/AEM.01550-17

[23] Xiong, X., Hu, Y., Yan, N., Huang, Y., Peng, N., Liang, Y. and Zhao, S. (2014) PCR-DGGE Analysis of the Microbial Communities in three Different Chinese "Baiyunbian" Liquor Fermentation starters. Journal of Microbiolog and Biotechnology, 24, 1088-1095. https://doi.org/10.4014/jmb.1401.01043

[24] Yao, S., Liu, Y., Zhang, M., Zhang, X., Li, H., Zhao, T., Xin, C., Xu, L., Zhang, B. and Cheng, C. (2014) Thermoactinomyces daqus sp. nov., a Thermophilic Bacterium Isolated from High-Temperature Daqu. International Journal of Systematic and Evolutionary Microbiology, 64, 206-210. https://doi.org/10.1099/ijs.0.055509-0

[25] Zhou, W., Liao, Z., Wu, Z., Suyama, T. and Zhang, W. (2021) Analysis of the Difference between Aged and Degenerated pit Mud Microbiome in Fermentation Cellars for Chinese Luzhou-Flavor Baijiu by Metatranscriptomics. Journal of the Science of Food and Agriculture, 101, 4621-4631. https://doi.org/10.1002/jsfa.11105 